\title{
Knowledge, Awareness and Attitude of Medical Students Regarding HPV Infection and HPV Vaccination
}

\author{
Aparna Narayana Gollu', Chaitali A Gore ${ }^{2}$
}

${ }^{1}$ Vydehi Medical College, Bangalore, India. ${ }^{2}$ Department of Community Medicine, Vydehi Institute of Medical Sciences and Research Centre, Bangalore, India.

\begin{abstract}
Background: Cervical cancer is the second commonest cancer among women in India and accounts for 6-29\% of cancers among women in India. Human Papilloma Virus (HPV) is a causative agent of the disease. Recent advances in technology have led to introduction of vaccine to prevent HPV infection. The current study aims to assess the awareness among medical students about HPV infection as a causative factor for cervical cancer and their knowledge about HPV vaccination. Assessing the knowledge of vaccination among medical students helps us to understand the level of awareness regarding the same among future doctors. Methods: A questionnaire based study was done on $150 \mathrm{MBBS}$ students from $2^{\text {nd }}$ and $3^{\text {rd }}$ year of Vydehi Medical College, Bangalore, Karnataka, India. Questionnaire consisted of 16 questions of multiple choice type and results were analysed using percentages and chi square test. P value $<0.05$ was considered significant. Results: Knowledge regarding HPV as a causative agent for cervical cancer was found in 67 (95.7\%) of male students and $79(98.8 \%)$ of female students with no statistically significant difference. Awareness about availability of HPV vaccine was seen in 66 $(82.5 \%)$ females as compared to $50(71.4 \%)$ males with a p value of 0.078 , which was not statistically significant. Complete vaccination status was seen in $3(4.3 \%)$ male students and $11(13.8 \%)$ female students with a p value of 0.041 and this association was statistically significant. $1(1.42 \%)$ male student and $1(1.25 \%)$ female student received incomplete vaccination. $25(35.7 \%)$ males and $74(92.5 \%)$ females were willing to get vaccinated with HPV vaccine with $p$ value 0.000 , and the association was statistically significant. Conclusion: There was good knowledge among medical students regarding cervical cancer and its prevention. But knowledge regarding HPV vaccine was poor among both males and females. Willingness to get vaccinated in male students was very less compared to female students.
\end{abstract}

Keywords: HPV vaccine- medical students- cervical cancer- HPV infection- Human Papilloma Virus

Asian Pac J Cancer Care, 6 (1), 41-46

Submission Date: 09/25/2020 Acceptance Date: 02/08/2021

\section{Introduction}

Cervical cancer is the second commonest cancer among women in India and Human Papilloma Virus (HPV) is an important causative agent of the disease [1]. Today we have vaccination available to prevent HPV infection. There is a need to study the awareness regarding HPV vaccination and take measures to improve the utilization of vaccination.

Cervical cancer accounts for 6-29\% of cancers among women in India [2]. A total of 96,922 new cervical cancer cases are diagnosed annually in India [3]. There are 432.2 million women in India who are aged 15 years and above and are at a risk of developing cervical cancer [4].

Cervical cancer is responsible for 60,078 deaths annually in India [3]. It ranks as the $2^{\text {nd }}$ leading cause of female cancer related deaths in India [1].

HPV viral infection spread by Human Papilloma Virus types 16 and 18 is implicated in $70 \%$ of cervical cancers, $90 \%$ of anal cancers and also in other genital cancers such as vulval cancer and vaginal cancer. HPV is proven to cause head and neck cancers apart from cervical cancer [5].

In a study conducted among Iranian women in

Corresponding Author:

Dr. Aparna Narayana Gollu

Vydehi Medical College, Bangalore, India.

Email: aparnanarayanag@gmail.com 
2013-16, prevalence of HPV infection was found to be $29.3 \%$ [6]. In the same study, among the HPV positive subjects, high-risk and low-risk HPV subtypes were found $67.2 \%$ and $52.0 \%$, respectively [6]. A study was conducted at rural Philippines in 2020 among the community which inferred that only $13.9 \%$ underwent cervical cancer screening [7]. In a study conducted among Thai women in $2020,46 \%$ of the participants were found to have poor knowledge regarding HPV infection and HPV vaccination [8].

Recent advances in technology have led to introduction of HPV vaccine to prevent HPV infection, which will directly help in reducing the incidence of cervical, ano-genital cancers and genital warts.

Vaccination is also recommended for boys as it is also implicated in penile, ano-rectal and oral cancer. Males also have a role in transmission of HPV infection to females [9].

As the HPV vaccine is a recent introduction and is targeted towards 9-26 age group, the awareness about this vaccine in the general population appears to be less. 9-14 years is the ideal age for administering this vaccine because it provides maximum immunogenicity of the vaccine at that age [10].

In a study conducted in Mangalore among medical students, $78.35 \%$ students were aware about cervical cancer prevention; $82.47 \%$ were aware that cervical cancer is caused by virus; $74.22 \%$ were aware about the availability of the vaccine [11]. In a study conducted in Manipal among medical students, only $28.4 \%$ of male students were aware that there is a need for vaccination in men [12]. The HPV vaccine is a newer addition in the universal immunization schedule. Hence its awareness is less compared to other vaccines.

Assessing the knowledge of vaccination among medical students helps us to understand the level of awareness regarding the same among future doctors.

Knowledge about cervical cancer symptoms can help in early detection and treatment of cervical cancer. After finding out the vaccination status, it will guide us to conduct appropriate awareness programs and motivate the students to get vaccinated.

The present study was done with the following objectives:

1. To assess the awareness about HPV virus infection as causative factor for cervical cancer.

2. To assess the knowledge about availability of HPV vaccination.

3. To assess the attitude towards getting vaccinated.

4. To assess the vaccination status among the medical students surveyed.

\section{Materials and Methods}

A cross sectional study was conducted on students in second and third year MBBS in 2019-2020 at Vydehi Institute of Medical Sciences and Research Centre, Bangalore, Karnataka, India.

Inclusion criteria was students willing to participate in study, studying in $2^{\text {nd }}$ and $3^{\text {rd }} \mathrm{MBBS}$ and aged between
18-25 years. Exclusion criteria was those who were not willing to participate in study.

A sample of 150 students (students of $2^{\text {nd }}$ and $3^{\text {rd }}$ MBBS) was chosen with a margin of error of $5 \%$. Permission was obtained from the Institutional Ethical Committee to conduct the study. The subjects were explained about the nature of the study. After obtaining written informed consent, questionnaire was administered to $2^{\text {nd }}$ and $3^{\text {rd }}$ year MBBS students. Informed consent and questionnaire were administered separately to maintain anonymity. For collection of data, questionnaire was devised from cervical cancer awareness measure tool kit version 2.0 and was modified [13]. Questionnaire consisted of 16 questions out of which, 12 questions assessed knowledge, 2 questions assessed attitude and 2 questions assessed practice regarding HPV infection and HPV vaccinations. Questions were of multiple choice type of which, the participants were asked to choose single or multiple responses wherever applicable. Questions on attitude and practice were of yes or no type.

Knowledge was assessed using questions on risk factors, causative agent, screening methods of cervical cancer. In the question on risk factors, 4 correct risk factors were given and inference was made on the each risk factor chosen in percentage. Similarly, the question: common cancers among women in India; was assessed with 2 out of 4 correct answers in the options.

Questions on awareness of availability of vaccine, whether vaccine is given to boys; were used to assess knowledge regarding HPV vaccine with a yes or no type of answering. Question on right age group for vaccination had 1 out of 4 correct answers in the options.

Attitude was assessed based on willingness to get vaccinated and to recommend the vaccine to a female relative with a yes or no type of answering.

A correct response to each of the questions and each right answer in a multiple answer type was given 1 point. A wrong answer in each question was given 0 points.

Percentages based on right answers were calculated and compared for each question separately for both male and female students and also compared between $2^{\text {nd }}$ and $3^{\text {rd }}$ year students.

The response was noted and statistical analysis was done.

\section{Statistical analysis}

Data was entered on excel sheet and was analysed using Statistical Package for Social Sciences (SPSS) ver.21 software.

Data was analysed using percentages and chi-square tests and results were obtained. In chi square tests, $p$ value $<0.05$ was considered significant.

\section{Results}

A total of 150 medical students participated in the study. Among them, $70(46.7 \%)$ were males and 80 $(53.3 \%)$ were females. $68(45.3 \%)$ students were studying in $2^{\text {nd }}$ year whereas $82(54.7 \%)$ were studying in $3^{\text {rd }}$ year. The ages ranged from 19-23 years and most of them were 
Table 1. Demographic Details of the Participants

\begin{tabular}{lcc}
\hline Demographic details & & $\mathrm{n}(\%)$ \\
\hline Age (years) & 19 & $18(12 \%)$ \\
& 20 & $58(38.7 \%)$ \\
& 21 & $55(36.7 \%)$ \\
& 22 & $16(10.7 \%)$ \\
Sex & 23 & $3(2 \%)$ \\
\multirow{2}{*}{ Year of study } & Male & $70(46.7 \%)$ \\
& Female & $80(53.3 \%)$ \\
& $2^{\text {nd }}$ year & $68(45.3 \%)$ \\
& $3^{\text {rd }}$ year & $82(54.7 \%)$ \\
\hline
\end{tabular}

$20(38.7 \%)$ and $21(36.7 \%)$ years old as shown in Table 1.

\section{Knowledge regarding cervical cancer}

In a question about the most common cancers among women in India, $44(29.3 \%)$ participants chose breast cancer, $68(45.3 \%)$ participants chose cervical cancer and $32(21.3 \%)$ chose both breast and cervical cancer as shown in Table 2. More number of female students as compared to male students had knowledge about this and this association was statistically significant.

Knowledge regarding HPV virus as a causative agent for cervical cancer was found in $67(95.7 \%)$ males and $79(98.8 \%)$ females. Where as $66(97.1 \%)$ from $2^{\text {nd }}$ year and $80(97.6 \%)$ from $3^{\text {rd }}$ year knew that cervical cancer is caused by HPV virus as shown in Table 2.

Among male students, 17 (24.3\%), 13 (18.6\%), $53(74.3 \%)$ and $41(58.6 \%)$ of the students correctly identified risk factors for cervical cancer to be early marriage, early child birth, multiple sexual partners and infections respectively. Among female students, 20 (25\%), 20 (25\%), 59 (73.8\%), 41 (51.3\%) of students could correctly identify early marriage, early child birth, multiple sexual partners and infections respectively as the risk factors of cervical cancer.

A question was asked regarding the screening method for cervical cancer where $63(90 \%)$ of males and
75 (93.8\%) of the females chose Pap smear as the right screening method. With respect to the year of study, 79 $(96.3 \%)$ from $3^{\text {rd }}$ year as compared to $57(83.8 \%)$ from $2^{\text {nd }}$ year were aware of the right screening method and this association was statistically significant as shown in Table 2.

When asked whether cervical cancer can be treated if detected early,65 (92.9\%) males and 73 (91.2\%) females answered positively. $61(89.7 \%)$ from $2^{\text {nd }}$ year and 77 $(93.9 \%)$ from $3^{\text {rd }}$ year answered positively as shown in Table 2.

\section{Knowledge regarding HPV vaccine}

$66(82.5 \%)$ females as compared to $50(71.4 \%)$ males were aware about the availability of HPV vaccine for cervical cancer. $74(90.2 \%)$ students from $3^{\text {rd }}$ year as compared to $42(61.8 \%)$ students from $2^{\text {nd }}$ year knew about the availability of HPV vaccine and this association was statistically significant as shown in Table 2.

When asked about the right age group for vaccination, and $73(91.2 \%)$ females as compared to $50(71.4 \%)$ males gave the correct response and this association was statistically significant. The correct response regarding right age group for vaccination was chosen by 42 (61.8\%) students from $2^{\text {nd }}$ year $74(90.2 \%)$ students from $3^{\text {rd }}$ year as shown in Table 2.

Only 43 (61.4\%) males knew that HPV vaccine can be given to boys whereas, $54(67.5 \%)$ females were aware of this fact as shown in Table 2.

$62(88.6 \%)$ male students and $72(90 \%)$ female students agreed that women who are already vaccinated need cervical cancer screening. $59(86.8 \%)$ students from $2^{\text {nd }}$ year and $75(91.5 \%)$ students from $3^{\text {rd }}$ year agreed to the same as shown in Table 2.

Among the participants, sources of knowledge and information on HPV vaccine was found in $122(81.3 \%)$, $41(27.3 \%), 17$ (11.3\%), 45 (30\%), 64 (42.7\%), 6 (4\%) as medical school teachings, friends, newspaper, books, internet and television, respectively.

Table 2. Knowledge Regarding Cervical Cancer and HPV Vaccine

\begin{tabular}{|c|c|c|c|c|c|c|}
\hline Knowledge regarding cervical cancer and HPV vaccine & $\begin{array}{l}\text { Male } \\
\mathrm{n}(\%)\end{array}$ & $\begin{array}{c}\text { Female } \\
\mathrm{n}(\%)\end{array}$ & $\mathrm{p}$ value & $\begin{array}{c}2^{\text {nd }} \text { year } \\
\text { n (\%) }\end{array}$ & $\begin{array}{c}3^{\text {rd }} \text { year } \\
\text { n (\%) }\end{array}$ & $\mathrm{p}$ value \\
\hline Most common cancers among women in India & & & & - & - & - \\
\hline Breast cancer & $27(38.6 \%)$ & $17(21.2 \%)$ & 0.009 & & & \\
\hline Cervical cancer & $29(41.4 \%)$ & $39(48.8 \%)$ & & & & \\
\hline Both & $10(14.3 \%)$ & $22(27.5 \%)$ & & & & \\
\hline HPV as a causative agent* & $67(95.7 \%)$ & $79(98.8 \%)$ & 0.261 & $66(97.1 \%)$ & $80(97.6 \%)$ & 0.616 \\
\hline Pap smear as a screening method* & $63(90 \%)$ & $75(93.8 \%)$ & 0.293 & $58(85.3 \%)$ & $80(97.6 \%)$ & 0.006 \\
\hline Can be treated if detected early* & $65(92.9 \%)$ & $73(91.2 \%)$ & 0.478 & $61(89.7 \%)$ & $77(93.9 \%)$ & 0.26 \\
\hline Availability of HPV vaccine** & $50(71.4 \%)$ & $66(82.5 \%)$ & 0.078 & $42(61.8 \%)$ & $74(90.2 \%)$ & 0.000 \\
\hline Right age group** & $50(71.4 \%)$ & $73(91.2 \%)$ & 0.002 & $54(79.4 \%)$ & $69(84.1 \%)$ & 0.295 \\
\hline Recommended to boys** & $43(61.4 \%)$ & $54(67.5 \%)$ & 0.272 & $39(57.4 \%)$ & $58(70.7 \%)$ & 0.062 \\
\hline Screening required after vaccination** & $62(88.6 \%)$ & $72(90 \%)$ & 0.491 & $59(86.8 \%)$ & $75(91.5 \%)$ & 0.253 \\
\hline
\end{tabular}

*knowledge regarding cervical cancer; **knowledge regarding HPV vaccine 
Table 3. Practice Regarding HPV Vaccination

\begin{tabular}{lcccccc}
\hline Practice regarding HPV vaccination & $\begin{array}{c}\text { Male } \\
\mathrm{n}(\%)\end{array}$ & $\begin{array}{c}\text { Female } \\
\mathrm{n}(\%)\end{array}$ & $\mathrm{p}$ value & $\begin{array}{c}2^{\text {nd }} \text { year } \\
\mathrm{n}(\%)\end{array}$ & $\begin{array}{c}3^{\text {rd }} \text { year } \\
\mathrm{n}(\%)\end{array}$ & $\mathrm{p}$ value \\
\hline Initiated vaccination & $4(5.7)$ & $12(15)$ & 0.056 & $9(13.2)$ & $7(8.5)$ & 0.253 \\
Completed vaccination & $3(4.3)$ & $11(13.8)$ & 0.041 & $8(11.8)$ & $6(7.3)$ & 0.257 \\
\hline
\end{tabular}

Table 4. Attitude Regarding HPV Vaccination

\begin{tabular}{lcccccc}
\hline Attitude regarding HPV vaccination & $\begin{array}{c}\text { Male } \\
\mathrm{n}(\%)\end{array}$ & $\begin{array}{c}\text { Female } \\
\mathrm{n}(\%)\end{array}$ & $\mathrm{p}$ value & $\begin{array}{c}2^{\text {nd }} \text { year } \\
\mathrm{n}(\%)\end{array}$ & $\begin{array}{c}3^{\text {rd }} \text { year } \\
\mathrm{n}(\%)\end{array}$ & $\mathrm{p}$ value \\
\hline Willing to get vaccinated & $25(35.7)$ & $74(92.5)$ & 0.000 & $47(69.1)$ & $52(63.4)$ & 0.288 \\
Recommend vaccination to a female relative & $64(91.4)$ & $73(91.2)$ & 0.601 & $65(95.6)$ & $72(87.8)$ & 0.079 \\
\hline
\end{tabular}

\section{Practice regarding HPV vaccination}

$3(4.3 \%)$ of the male students were fully vaccinated whereas, 11 (13.8\%) females were fully vaccinated and this association was statistically significant. Apart from this, $1(1.42 \%)$ male student and $1(1.25 \%)$ female student was found to have taken partial course of vaccination as shown in Table 3.

\section{Attitude regarding $H P V$ vaccination:}

Among the participants, 74 (92.5\%) female students as compared to $25(35.7 \%)$ male students were willing to get vaccinated and this association was statistically significant. 47 (69.1\%) students and 52 (63.4\%) students from $2^{\text {nd }}$ and $3^{\text {rd }}$ year respectively were willing to get vaccinated as shown in Table 4.

Among the participants, 64 (91.4\%) males and $73(91.2 \%)$ females were ready to recommend the vaccine to a female relative. With respect to the year of study, $65(95.6 \%)$ students from $2^{\text {nd }}$ year and $72(87.8 \%)$ students from $3^{\text {rd }}$ year would recommend the vaccine to a female relative as shown in Table 4.

\section{Discussion}

The aim of our study was to assess the awareness and acceptability of HPV vaccine among medical students. In this study which was conducted among 150 medical students, 70 were males and 80 were females.

According to our study, $67(95.7 \%)$ males and 79 (98.8\%) females were aware that HPV virus causes cervical cancer. To compare, in a study by Al-Darwish et al. [14] in Saudi Arabia among medical students, 45\% of males and $53.2 \%$ females were able to identify HPV infection as the cause for cervical cancer. This shows that there is a huge difference in the knowledge regarding causative agent between the two studies with more students being aware in the present study.

In the current study, $66(82.5 \%)$ females and 50 $(71.4 \%)$ males were aware that HPV vaccine is available. A study conducted by Pandey et al. [12] at Manipal among medical students showed that $65.7 \%$ males and $83.1 \%$ females knew about the availability of HPV vaccine. An increased percentage of male students were aware in the current study when compared. In a study conducted by Borlu et al. [15] in Turkey among undergraduate university students, 160 (62.5\%) of medical students were aware about the availability of HPV vaccine compared to $116(66.5 \%)$ medical students in our study.

In the current study, awareness regarding vaccination advised to men was found to be in $43(61.4 \%)$ males and $54(67.5 \%)$ females. In a study conducted by Yam et al. [16] in Hong Kong on 420 medical and non medical students, $84 \%$ of medical students agreed that vaccination was recommended to men when compared to 97 (64.7\%) medical students in our study.

The current study shows that $25(35.7 \%)$ males and $74(92.5 \%)$ females were willing to get vaccinated. Also, $64(91.4 \%)$ males and $73(91.2 \%)$ females were willing to recommend the vaccine to a female relative. This indicates that there is lack of awareness among males regarding vaccination advised for men. This is also reflected in the fact that only $35.7 \%$ males were willing for vaccination for themselves compared to $91.4 \%$ males willing to advise vaccination to a female relative. In a study conducted by $\mathrm{Fu}$ et al. [17] among medical students in Chong-qing, China, $57.2 \%$ males and $78.5 \%$ females were willing to receive or advise HPV vaccination.

In the present study, only $1(1.42 \%)$ male student had received partial course of vaccination with $3(4.3 \%)$ of the males having received complete vaccination. $11(13.8 \%)$ females had received complete vaccination with $1(1.25 \%)$ having received partial course of vaccination. In a study conducted by Berenson et al. [18] in U.S. among 231 medical students, $81(66.4 \%)$ female students and $16(14.7 \%)$ male students reported initiating the vaccine. Among all the participants in our study only 14 (9.3\%) of the participants had received complete vaccination in comparison to $75(35.2 \%)$ students with complete vaccination status according to a study conducted by Afonso et al. [19] in the U.S. among 213 medical students. In the same study, partially vaccinated students were 19 $(8.9 \%)$ as compared to $2(1.33 \%)$ in this study.

Regarding risk factors for cervical cancer, 37 (52.9\%) male students and $43(53.8 \%)$ female students could identify only one risk factor correctly. Only 7 (10\%) male students and $8(10 \%)$ female students could correctly identify early marriage, early child birth, multiple sexual partners and infections as risk factors for cervical cancer. $52(74.3 \%)$ male and $59(73.8 \%)$ female students identified multiple sexual partners as a risk factors for cervical cancer. 41 (58.6\%) male and 41 (51.3\%) female students identified infections as a risk factor for cervical 
cancer.

Pap smear as screening method for cervical cancer was known by $90.1 \%$ participants in a study conducted by Maharajan et al. [20] in Malaysia among 305 medical students. In our study, $138(92 \%)$ of the participants have shown this knowledge. This knowledge seems to comparable in both the studies.

In a question regarding need for cervical cancer screening after vaccination, $59(86.8 \%)$ from $2^{\text {nd }}$ year and $75(91.5 \%)$ from $3^{\text {rd }}$ year answered positively in the present study. In a study conducted by Yam et al. [16] in Hong Kong among 420 medical and non medical students, 88 $(86.3 \%)$ medical students below $3^{\text {rd }}$ year and $141(99.3 \%)$ medical students from and above $3^{\text {rd }}$ year have this knowledge. This data appears to be similar to our study.

Further studies can be conducted to find out the root cause for the poor vaccination status and through those studies, measures can be taken to address the issue.

In conclusion, awareness about HPV vaccination as causative factor for cervical cancer was found in 67 $(95.7 \%)$ males and $79(98.8 \%)$ females. $66(82.5 \%)$ females compared to $50(71.4 \%)$ males were aware about the availability of HPV vaccine. Only one male student was found to have taken an incomplete course of vaccination. In comparison, 12 (15\%) female students were found to have completed full course of vaccination and 1 female student having taken incomplete course of vaccination. This study found that $64(91.4 \%)$ males and $73(91.2 \%)$ females were willing to recommend the vaccine to a female relative.

The conclusion from the current study is that there is good knowledge among medical students regarding cervical cancer and its prevention. But knowledge regarding HPV vaccine i.e., availability of the vaccine, right age group for vaccination and vaccination recommended for males needs to improve. Vaccination status is poor among both males and females. Willingness to get vaccinated in male students was very less compared to female students. Hence, there seems to be a need to motivate male students towards vaccination.

Therefore, more awareness has to be created about HPV vaccine among medical students through emphasis in the curriculum.

\section{Acknowledgements}

"This work was supported and funded by Indian Council of Medical Research under its ICMR STS-2019 programme"

\section{Statement conflict of interest}

This research project has been funded and approved by Indian Council of Medical Research under the ICMR STS-2019 program.

With reference to the cervical CAM toolkit used to devise the questionnaire for this study:

'This survey instrument (the Cervical CAM) was developed by the UCL Health Behaviour Research Centre, in collaboration with the Department of Health Cancer Team and The Eve Appeal, with funding from The Eve
Appeal. It forms part of the Cervical Cancer Awareness and Symptoms Initiative (CCASI). It is based on a generic CAM developed by Cancer Research UK, University College London, King's College London and Oxford University in 2007-08.'

\section{References}

1. Bruni L, Albero G, Serrano B, Mena M, Gómez D, Muñoz J, Bosch F, de Sanjosé S. ICO/IARCInformation Centre on HPV and Cancer (HPV Information Centre). "Human Papillomavirus and Related Diseases in India". 2019,June,17. accessed on 2019, October,30;.

2. Bobdey S, Sathwara J, Jain A, Balasubramaniam G. Burden of cervical cancer and role of screening in India. Indian Journal of Medical and Paediatric Oncology. 2016;37(4):278. https:// doi.org/10.4103/0971-5851.195751

3. National Institute of Cancer Prevention and Research (NICPR). "India Against Cancer". 2011,October,19. http://cancerindia. org.in/cervical-cancer/. accessed on 2019,October,30;

4. Trivedi V, Kumar R, Rani R, Chauhan R, Kumari A. Cervical cancer awareness in Bihar, India: Lots of light but no illumination. IOSR Journal of Dental and Medical Sciences. 2015 April;14(4):88-92.

5. De Martel C, Ferlay J, Franceschi S, Vignat J, Bray F, Forman D, et al. Global burden of cancers attributable to infections in 2008: a review and synthetic analysis. Lancet Oncol. 2012;13(6):607-15.

6. Chalabiani S, Khodadad Nazari M, Shabani M, Razavi Davoodi N, Sarafnejad A, Amirzargar AA. Retrospective Analysis of Prevalence of High-risk and Low-risk Human Papillomavirus (HPV) Genotypes in Iranian Women During 2013-2016. Asian Pacific Journal of Cancer Biology. 2017 Dec 25;2(4):85-90. https://doi.org/10.31557/ apjcb.2017.2.4.85-90

7. Imoto A, Honda S, Llamas-Clark EF. Human Papillomavirus and Cervical Cancer Knowledge, Perceptions, and Screening Behavior: A Cross-Sectional Community-Based Survey in Rural Philippines. Asian Pacific Journal of Cancer Prevention. 2020 Nov 01;21(11):3145-3151. https://doi. org/10.31557/apjcp.2020.21.11.3145

8. Likitdee N, Kietpeerakool C, Chumworathayi B, Temtanakitpaisan A, Aue-aungkul A, Nhokaew W, Jampathong N. Knowledge and Attitude Toward Human Papillomavirus Infection and Vaccination among Thai Women: A Nationwide Social Media Survey. Asian Pacific Journal of Cancer Prevention. 2020 Oct 01;21(10):28952902. https://doi.org/10.31557/apjcp.2020.21.10.2895

9. Palefsky JM. Human Papillomavirus-Related Disease in Men: Not Just a Women's Issue. Journal of Adolescent Health. 2010 04;46(4):S12-S19. https://doi.org/10.1016/j. jadohealth.2010.01.010

10. Dillner J, Arbyn M, Unger E, Dillner L. Monitoring of human papillomavirus vaccination. Clinical \& Experimental Immunology. 2010 Nov 09;163(1):17-25. https://doi. org/10.1111/j.1365-2249.2010.04268.x

11. M. R, Sadiqunissa S, Ahmed M. Awareness and knowledge of human papilloma virus (HPV) vaccine in prevention of cervical cancer among medical students. International Journal of Reproduction, Contraception, Obstetrics and Gynecology. 2018 Nov 26;7(12):5026. https://doi. org/10.18203/2320-1770.ijrcog20184960

12. Pandey D, Vanya V, Bhagat S, VS B, Shetty J. Awareness and Attitude towards Human Papillomavirus (HPV) Vaccine among Medical Students in a Premier Medical School in 
India. Wu JT. PLoS ONE. 201207 31;7(7):e40619. https:// doi.org/10.1371/journal.pone.0040619

13. cancerresearchuk.org. Cervical Cancer Awareness Measure Toolkit Version 2.1. https://www.cancerresearchuk.org/ sites/default/files/health_professional_cervical_cancer_ awareness_measure_toolkit_version_- $2.1 \_09.0 \overline{2} .11$.pdf. Accessed on 24/01/2019..

14. Al-Darwish A, Al-Naim A, Al-Mulhim K, Al-Otaibi N, Morsi M, Aleem A. Knowledge about Cervical Cancer Early Warning Signs and Symptoms, Risk Factors and Vaccination among Students at a Medical School in Al-Ahsa, Kingdom of Saudi Arabia. Asian Pac J Cancer Prev. 2014;15(6):2529-32.

15. Borlu A, Gunay O, Balcı E, Sagıroglu M. Knowledge and Attitudes of Medical and Non-Medical Turkish University Students about Cervical Cancer and HPV Vaccination. Asian Pac J Cancer Prev. 2016;17(1):299-303.

16. Yam P, Lam P, Chan T, Chau K, Hsu M, Lim Y, et al. A Cross Sectional Study on Knowledge, Attitude and Practice related to Human Papillomavirus Vaccination for Cervical Cancer Prevention between Medical and Non-Medical Students in Hong Kong. Asian Pac J Cancer Prev. 2017;18(6):1689-95.

17. Fu C, Pan X, Zhao Z, Saheb-Kashaf M, Chen F, Wen Y, et al. Knowledge, perceptions and acceptability of HPV vaccination among medical students in Chongqing, China. Asian Pac J Cancer Prev. 2014;15(15):6187-93.

18. Berenson AB, Hirth JM, Fuchs EL. US medical students' willingness to offer the HPV vaccine by vaccination status. Vaccine. 2017 03;35(9):1212-1215. https://doi. org/10.1016/j.vaccine.2017.01.028

19. Afonso NM, Kavanagh MJ, Swanberg SM, Schulte JM, Wunderlich T, Lucia VC. Will they lead by example? Assessment of vaccination rates and attitudes to human papilloma virus in millennial medical students. BMC Public Health. 201701 06;17(1). https://doi.org/10.1186/s12889016-3969-x

20. Maharajan M, Rajiah K, Fang-Num K, Yong N. Knowledge of Human Papillomavirus Infection, Cervical Cancer and Willingness to pay for Cervical Cancer Vaccination among Ethnically Diverse Medical Students in Malaysia. Asian Pac J Cancer Prev. 2015;16(14):5733-9.

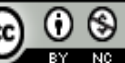

This work is licensed under a Creative Commons AttributionNon Commercial 4.0 International License. 